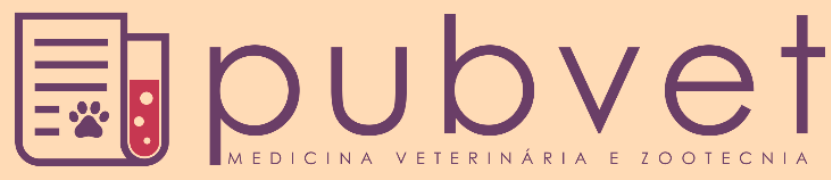

https://doi.org/10.31533/pubvet.v15n09a916.1-5

\title{
Primeiro registro de felinos domésticos acometidos por esporotricose na região de Aimorés, Minas Gerais: Relato de caso
}

\author{
Monara Guisolfi Menegassi ${ }^{1}{ }^{\theta}$, Lizandra $\operatorname{Rocha}^{1}{ }^{\theta}$, Jéssica Miranda $\operatorname{Cota}^{2} * \bullet \oplus$, Clairton \\ Marcolongo Pereira $^{2} \odot$ (D), Rubian Garcia Langa ${ }^{3} \bullet$, Luiz Alexandre Moscon ${ }^{2} \bullet$, Alana Carmela \\ Ferrareis Cerqueira $^{4} \theta$ \\ ${ }^{1}$ Acadêmica no Centro Universitário do Espírito Santo, Departamento de Medicina Veterinária. Colatina - ES Brasil.
${ }_{2}^{2}$ Professor (a) no Centro Universitário do Espírito Santo, Departamento de Medicina Veterinária. Colatina - ES Brasil.
${ }^{3}$ Médico Veterinário Autônomo. Aimorés - MG Brasil.
${ }^{4}$ Residente no Centro Universitário do Espírito Santo, Departamento de Medicina Veterinária. Colatina - ES Brasil.
${ }^{*}$ Autor para correspondência, E-mail: jessmirandac@ gmail.com
}

Resumo. A esporotricose é uma doença zoonótica causada pelo fungo Sporothrix schenckii, sua infecção ocorre através do processo de inoculação direta na pele. Objetivouse relatar os três primeiros casos de esporotricose acometendo gato doméstico, na cidade de Aimorés em Minas Gerais. Os três felinos eram machos, Pelo Curto Brasileiro (PCB), com idades de cinco e oito anos, viviam de forma semi-domiciliada, apresentando histórico de lesões dermatológicas semelhantes com evolução de duas a quatro semanas. Foram observadas lesões exulceradas e distribuídas em várias regiões do corpo. Realizou-se o exame citopatológico utilizando a técnica de imprinting das lesões. As estruturas encontradas foram compatíveis com Sporothrix Scheckii. O itraconazol na dose de $5 \mathrm{mg} / \mathrm{kg}$ via oral, a cada 12 horas e por oito semanas foi o fármaco escolhido para o tratamento. Sendo assim, vale ressaltar que a esporotricose é uma patologia que acomete felinos, principalmente aqueles com acesso à rua, e deve ser considerada como diagnóstico diferencial de lesões nodulares ou ulceradas em felinos.

Palavras chave: Felino, infecção fúngica, Sportothrix schenkii, zoonose

\section{First registration of domestic felines affected by sporotricose in the region of Aimorés, Minas Gerais: Case report}

\begin{abstract}
Sporotrichosis is a zoonotic disease caused by the fungus Sporothrix schenckii, its infection occurs through the process of direct inoculation in the skin. The objective was to report the first three cases of sporotrichosis affecting domestic cats, in the city of Aimorés in Minas Gerais. The three cats were male, Pelo Curto Brasileiro (PCB), aged five and eight years old, living in a semi-domiciled manner, reporting a history of similar dermatological lesions with the evolution of two to four weeks. Exulcerated lesions were observed and distributed in several regions of the body. Cytopathological examination was performed using the technique of imprinting the lesions. The found structures were compatible with Sporothrix Scheckii. Itraconazole at a dose of $5 \mathrm{mg} / \mathrm{kg}$ orally, every 12 hours and for eight weeks was the drug chosen for the treatment. Therefore, it is worth mentioning that sporotrichosis is a pathology that affects cats, especially those with access to the street, and should be considered as a differential diagnosis of nodular or ulcerated lesions in cats.
\end{abstract}

Keywords: cat, fungal infection, Sporothrix schenckii, zoonosis 


\section{Primer registro de gatos domésticos afectados por esporotricosis em la región Aimorés, Minas Gerais: Reporte de caso}

Resumen. La esporotricosis es una enfermedad zoonótica causada por el hongo Sporothrix schenckii, su infección se produce a través del proceso de inoculación directa en la piel. El objetivo fue reportar los tres primeros casos de esporotricosis que afectan a los gatos domésticos en la ciudad de Aimorés, Minas Gerais. Los tres felinos eran machos, de pelo corto brasileño (PCB), de cinco y ocho años de edad, que vivían semidomesticados, presentando una historia de lesiones dermatológicas similares con una evolución de dos a cuatro semanas. Se observaron lesiones exulceradas y distribuidas en varias regiones del cuerpo. El examen citopatológico de las lesiones se realizó mediante la técnica de imprinting. Las estructuras encontradas eran compatibles con Sporothrix scheckii. El itraconazol a una dosis de $5 \mathrm{mg} / \mathrm{kg}$ por vía oral, cada 12 horas, durante ocho semanas fue el fármaco elegido para el tratamiento. Por lo tanto, cabe señalar que la esporotricosis es una patología que afecta a los gatos, especialmente a los que tienen acceso a la calle, y debe considerarse como un diagnóstico diferencial de las lesiones nodulares o ulceradas en los gatos.

Palavras clave: Gato, infección por hongos, Sporothrix schenckii, zoonosis

\section{Introdução}

A esporotricose é uma zoonose causada pelo fungo Sporothrix schenckii e a infecção ocorre por processo de inoculação direta na pele (Barros et al., 2010). O fungo pode ser encontrado em matéria orgânica, solo, plantas e caules de árvores (Pereira et al., 2018). A disseminação da doença ocorre maioritariamente entre felinos machos não castrados (Meinerz et al., 2007). Atualmente, a esporotricose já foi relatada em diversos estados do Brasil, sendo na região sul os maiores focos. No estado do Rio Grande do Sul a doença já foi relatada em forma de surto, e requer atenção até os dias atuais (Gonçalves $\underline{\text { et al., 2019). Além disso, relatos de caso da doença em Minas Gerais já foram reportados (Barros et al., }}$ 2012).

Os sinais clínicos são caracterizados pela presença de úlceras, em sua maioria com secreção purulenta e/ou hemática, além de pápulas ou nódulos (Pires, 2017). Como são sinais clínicos pouco específicos, pode haver vários diagnósticos diferenciais, como criptococose, lepra felina, neoplasias, abcessos bacterianos, reação a diversos corpos estranhos, blastomicose e histoplasmose (Barros et al., 2012).

Para realização do diagnóstico é necessário a realização de cultura, exame histopatológico e citopatológico, sendo a cultura fúngica o exame de eleição para um diagnóstico definitivo. Os exames histopatológicos e citopatológicos são considerados auxiliares, em caso de impossibilidade de realização da cultura (Barros et al., 2012).

O fármaco comumente escolhido para o tratamento é o itraconazol. Além disso, esse medicamento possui poucos efeitos colaterais, o que favorece sua escolha, comparado a outros antifúngicos semelhantes (Almeida et al., 2018).

Este trabalho é o primeiro relato de esporotriocse em felinos domésticos naturalmente acometidos no município de Aimorés, no estado de Minas Gerais. O objetivo do trabalho é alertar os médicos veterinários da região para possíveis novos casos da enfermidade e prevenção de surtos.

\section{Relato do caso}

No ano de 2020 foram atendidos no Hospital Veterinário Joaquim Rossi - UNESC, três felinos domésticos com queixas semelhantes. Os três pacientes eram machos, Pelo Curto Brasileiro (PCB), com idades de cinco (2/3) e oito (1/3) anos. Os animais procediam do município de Aimorés, localizado no estado de Minas Gerais, onde viviam de forma semi-domiciliada. Os três animais residiam em locais diferentes, mas todos apresentavam histórico de lesões dermatológicas com evolução de duas a quatro semanas e os tutores negaram o prurido. $\mathrm{Na}$ avaliação dermatológica foram observadas lesões 
exulceradas (Figura 1), distribuídas nas regiões de cabeça e pescoço, pavilhão auricular, membros torácicos, dorso e face.

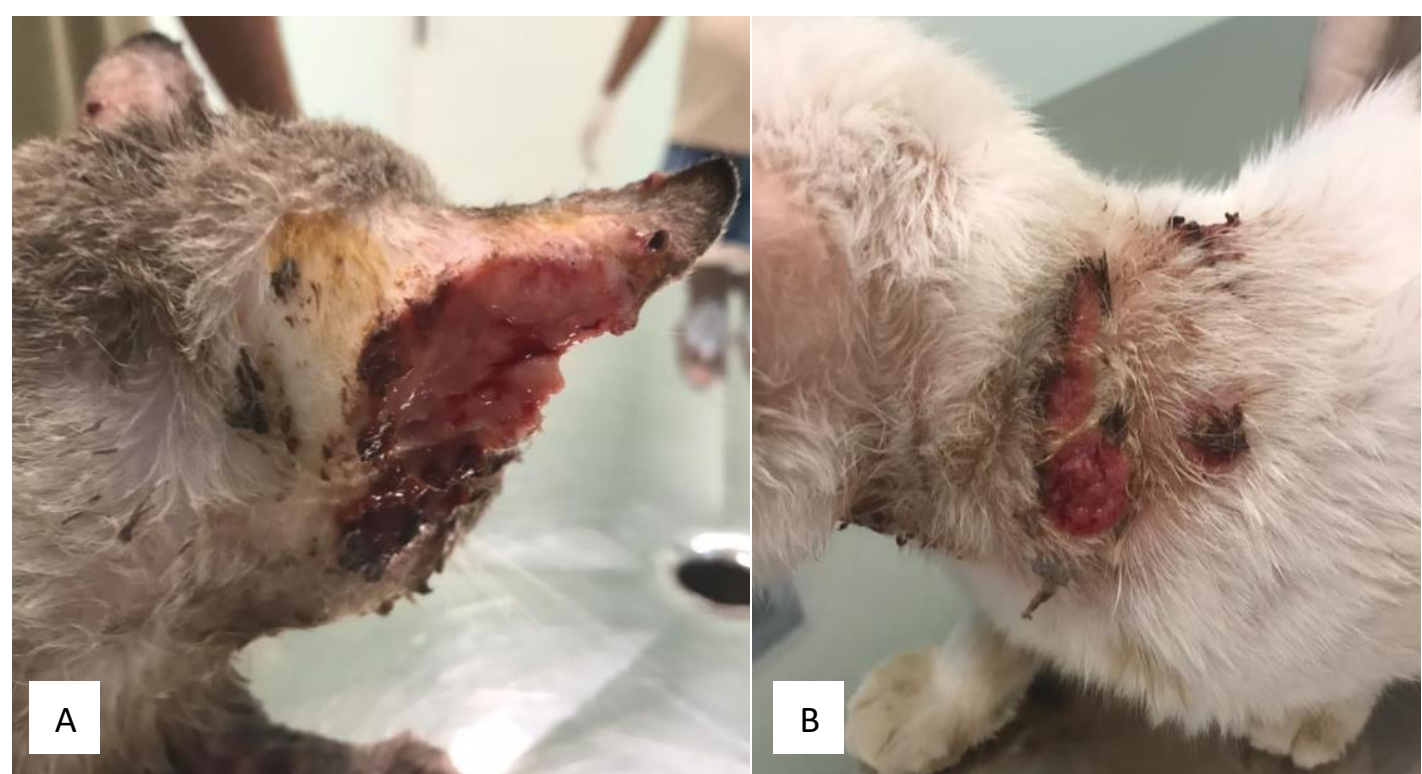

Figura 1. (A) Lesão exulcerada em borda de pavilhão auricular de um felino com esporotricose. (B) Lesão exulcerada em região cervical de um felino com esporotricose.

Foi realizado o exame citopatológico das lesões que os pacientes demonstraram. A técnica utilizada foi o imprinting das lesões. Posteriormente, as lâminas foram coradas com o corante do tipo Romanowsky.

Na citologia a celularidade era composta por neutrófilos e macrófagos em grande quantidade. Foram observados grande número de estruturas pleomórficas, com formato redondo a oval ou fusiformes (forma de charuto), apresentando um halo fino claro ao redor de um centro basofílico. Algumas destas estruturas encontram-se livres e outras fagocitadas dentro de macrófagos. Os achados foram compatíveis com Sporothrix schenckii (Figura 2). Não foi realizado o cultivo fúngico por restrições financeiras dos tutores.

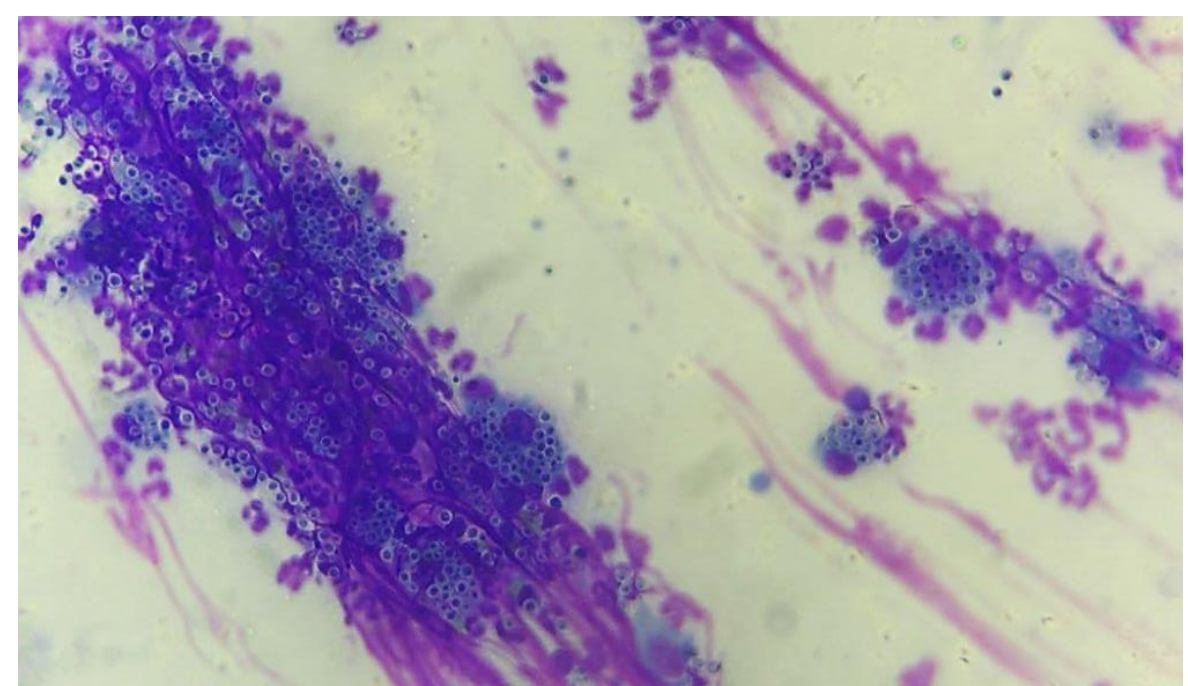

Figura 2. Grande quantidade de esporos fúngicos do tipo Sporothrix schenckii dentro do citoplasma de macrófagos e no meio extracelular (HE, 400x).

Para o tratamento foi prescrito itraconazol, na dose de $5 \mathrm{mg} / \mathrm{kg}$ por via oral a cada 12 horas, por oito semanas. Os casos foram notificados à vigilância sanitária de Aimorés-MG. Os animais não retornaram para o acompanhamento clínico. 


\section{Discussão}

A esporotricose é uma doença fúngica e infecciosa e tem como principal agente agressor o felino doméstico, sendo também reservatório e transmissor zoonótico para os humanos (Gremião et al., 2017; Pires, 2017). Os gatos descritos no relato eram machos e não castrados, de acordo com a literatura os mesmos são mais predispostos a desenvolver a doença do que as próprias fêmeas, isso por possuir hábitos comportamentais específicos (Pereira et al., 2018). Práticas inerentes à espécie, como afiar as unhas em caules de árvores, enterrar fezes e brigar com outros felinos por disputa territorial favorece a transmissão da doença (Marques-Melo et al., 2014).

Segundo Larsson (2011), as lesões exsudativas possuem rápida evolução, normalmente e frequentemente ocorrem em região cefálica, auricular, plano nasal e membros torácicos. No presente relato, os animais apresentaram lesões exulceradas, distribuídas nas regiões de cabeça e pescoço, pavilhão auricular, membros torácicos, dorso e face. Clinicamente, as manifestações da esporotricose felina podem ser confundidas com outras doenças infecto parasitárias, tais como a criptococose, a leishmaniose e outras afecções cutâneas, como atopia e, até mesmo, neoplasias, enfatizando a necessidade do diagnóstico laboratorial (Macêdo-Sales et al., 2018). Apesar da citopatologia retratar uma alternativa de diagnóstico rápido, de baixo custo e de fácil execução, é considerado um método presuntivo (Macêdo-Sales et al., 2018).

Em um estudo, a sensibilidade da citopatologia por imprint detectada foi maior (81,6\%) para um grupo de felinos assistido para o diagnóstico da esporotricose (INI/Fiocruz). O estudo validou a técnica como recurso seguro, rápido e de baixo custo para o diagnóstico presuntivo da esporotricose em gatos domésticos (Silva et al., 2015). No presente estudo, os achados a partir da citologia foram compatíveis com Sporothrix schenckii, portanto o diagnóstico é considerado definitivo quando obtido através do isolamento do agente etiológico em cultura fúngica (Reis et al., 2016).

O tratamento mais utilizado são os fármacos de ação antifúngica, o itraconazol é considerado o medicamento de eleição pertinente a sua segurança e eficácia, tornando-o excepcional ao ser comparado com outros fármacos desta mesma ação (Pereira et al., 2010). Outros tratamentos podem ser utilizados, como os halogenados (iodeto de potássio) e os alilamínicos (terbinafina), além do manuseio das lesões (Larsson, 2011). Independente do medicamento a ser utilizado, o tratamento deve se estender por semanas e orientam essa continuidade por dois a três meses após cicatrização das lesões (Pereira, 2018).

\section{Conclusão}

A esporotricose deve ser considerada um diagnóstico diferencial para lesões nodulares ou ulceradas em felinos que tem acesso à rua, mesmo em áreas não endêmicas. Apesar do exame citopatológico ser presuntivo para o diagnóstico da esporotricose, o mesmo se torna uma ferramenta de rápido resultado e baixo custo, facilitando, assim, a prevenção de possíveis surtos em determinada região.

\section{Referências bibliográficas}

Almeida, A. J., Reis, N. F., Lourenço, C. S., Costa, N. Q., Bernardino, M. L. A \& Vieira-da-Motta, O. (2018). Esporotricose em felinos domésticos (Felis catus domesticus) em Campos dos Goytacazes, RJ. Pesquisa Veterinária Brasileira, 38(7),1438-1443. 10.1590/1678-5150-PVB-5559

Barros, M. B. L., Schubach, T. P., Coll, J. O., Germião, I. D., Wanke, B., Shubach, A. (2010). Esporotricose: a evolução e os desafios de uma epidemia. Revista Panamericana de Salud Pública, 2010;27(6):455-60. Doi: 10.1590/S1020-49892010000600007

Barros, M. S.; Ferrari, H. J.; Rezende, R. S.; Faria, J. L. M. (2012). Esporotricose felina: primeiro relato de caso em Uberaba - Minas Gerais. Veterinária Notícias, Uberlândia, 18(2), 110-120.

Gonçalves, J. C., Gremião, I. D. F., Kölling, G., Duval, A. E. A., Ribeiro, P. M. T. (2019). Esporotricose: o gato e a comunidade. Enciclopédia Biosfera, v. 16, n. 29, p. 769-787. Doi: 10.18677/EnciBio_2019A62

Gremião, I. D. F.; Miranda, L. H. M. Reis, E. G., Rodrigues, A. M. \& Pereira, S. A. (2017). Zoonotic Epidemic of Sporotrichosis: Cat to Human Transmission. PLoS Pathogens, 13(1). Doi: 10.1371/journal.ppat. 1006077 
Larsson, C. E. (2011). Esporotricose. Revista Brasileira de Pesquisa Veterinária e Zootecnia. v.48, n.3. Doi: https://doi.org/10.11606/S1413-95962011000300010

Macêdo-Sales, P. A., da Silveira Souto, S. R. L., Destefani, C. A., Lucena, R. P., da Rocha, E. M. S. \& Baptista, A.R. S. (2018). Diagnóstico laboratorial da esporotricose felina em amostras coletadas no estado do Rio de Janeiro. Revista Pan-Amazônica de Saúde, 9(2):13-19. Doi: 10.5123/s21766 2232018000200002

Macêdo-Sales, P. A., Souto, S. R. L. S., Destefani, C. A., Lucena, R. P., Machado, R. L. D., Pinto, M. R., Rodrigues, A. M., Lopes-Bezerra, L M., Rocha, E. M. S. \& Baptista, A. R. S. (2018). Domestc feline contribuition in the transmission of Sporothrix in Rio de Janeiro State, Brazil: a comparison between infected and non-infected populations. BMC Veterinary Research, 14:19. Doi: 10.1186/s12917-018-1340-4

Marques-Melo, E. H., Lessa, D. F. S., Nunes, A. C. B. T., Chaves, K. P., Nascimento Porto, W. J. N., Notomi, M. K. \& Garrido, L. H. A. (2014). Felino doméstico como agente transmissor de esporotricose para humano: relato do primeiro caso no estado de alagoas. Revista Baiana de Saúde Pública, 38(2), 490-498. Doi: 10.5327/Z0100-0233-2014380200018.

Meinerz, A. R. M., Nascente, P. S., Shunch, L. F. D., Cleff, M. B., Santin, R., Brum, C. S., Nobre, M. O., Meireles, M. C. A., Mello, J. R. B. (2007). Suscetibilidade in vitro de isolados de Sporothrix schenckii frente à terbinafina e itraconazol. Revista da Sociedade Brasileira de Medicina Tropical 40(1):60-62. Doi: https://doi.org/10.1590/S0037-86822007000100012

Pereira, S. A., Passos, S. R., Silva, J. N., Gremião, I. D., Figueiredo, F. B., Teixeira, J. L. Monteiro, P. C. F., Schubach, T. M. P. (2010). Response to azolic antifungal agents for treating feline sporotrichosis. Veterinary Record. 166(10):290-4. Doi: 10.1136/vr.b4752

Pereira, S. A., Schubach, T. M. P., Gremião, I. D. F., da Silva, D. T., Figueiredo, F. B., Assis, N. V., Passos, S. R. L. (2018). Aspectos terapêuticos da esporotricose felina. Acta Scientiae Veterinariae. 37(4):311-321. 10.22456/1679-9216.16781

Pires, C. (2017). Revisão de literatura: esporotricose felina. Revista de Educação Continuada em Medicina Veterinária e Zootecnia do CRMV-SP, v. 15, n. 1, p. 16-23. Doi: https://doi.org/10.36440/recmvz.v15i1.36758

Reis, E. G., Schubach, T. M., Pereira, S. A., Silva, J. N., Carvalho, B. W., Quintana, M. S. B., Garemião, I.D. F. (2016). Association of itraconazole and potassium iodide in the treatment of feline sporotrichosis: a prospective study. Medical mycology. v. 54, n. 7, p. 684-690. Doi: $10.1177 / 1098612 \times 12441317$

Silva, J. N., Passos, S. R. L., Menezes, R. C., Gremião, I. D. F., Schubach, T. M. P., Oliveira, J. C., Figueiredo, F. A \& Pereira, A. S. (2015). Diagnostic accuracy assessment of cytopathological examination of feline sporotrichosis. Medical Mycology, 53(8):880-4. https://doi.org/10.1093/mmy/myv038

Histórico do artigo:

Recebido: 30 de maio de 2021

Aprovado: 2 de julho de 2021
Licenciamento: Este artigo é publicado na modalidade Acesso Aberto sob a licença Creative Commons Atribuição 4.0 (CC-BY 4.0), a qual permite uso irrestrito, distribuição, reprodução em qualquer meio, desde que o autor e a fonte sejam devidamente creditados. 